ripped up or walls built.

We cannot forecast the future without an understanding of the relationships between science, technology and the economy, because technical change is such an important determinant of the future. I have studied these questions for the Industrial Revolution using business accounts and histories of inventions. The steam engine, for instance, was an application of seventeenth-century science (the discoveries that the atmosphere has weight and that condensing steam creates a vacuum). By contrast, the cotton mills owed little to science and much to attempts to cut costs of relatively expensive employment ${ }^{16}$.

How has the balance between knowledge and incentives evolved? The more technology advances in response to economic incentives rather than 'random' scientific discoveries, the more feasible it is to direct the course of technical progress to benefit more people. Furthermore, the cotton mills of the Industrial Revolution increased the demand for workers without education, whereas more-recent technology requires more education. Why the difference? Will the recent trend of needing educated workers persist? If not, then the hope that a knowledge-based future will make everyone better off is doomed. .

Robert C. Allen is professor of economic history at New York University Abu Dhabi, United Arab Emirates; and senior research fellow at Nuffield College, Oxford, UK.

e-mail:bob.allen@nyu.edu

1. Acemoglu, D. \& Restrepo, P. NBER Working Paper No. 23285 (2017); available at http:// go.nature.com/2wabaab

2. Solow, R. M. Q. J. Econ. 70, 65-94 (1956).

3. http://go.nature.com/2yh9jve

4. Allen, R. C. Econ. Hist. Rev. 56, 403-443 (2003).

5. Allen, R. C. Global Economic History: A Very Short Introduction (Oxford, 2011).

6. Marx, K. Capital Vol. 1, English trans. (1887); available at http://go.nature.com/2ftxrww

7. Goldin, C. \& Katz, L. F. Q. J. Econ. $\mathbf{1 1 3}$, 693-732 (1998).

8. Acemoglu, D. J. Econ. Lit. 40, 7-72 (2002)

9. Kuznets, S. Am. Econ. Rev. 45, 1-28 (1955).

10.Atkinson, A. B., Piketty, T. \& Saez, E. J. Econ. Lit. 49, 3-71 (2011).

11. Milanovic, B. Global Inequality (Harvard Univ. Press, 2016)

12. Bourguigon, F. \& Morrison, C. Am. Econ. Rev. 92, 727-744 (2002).

13.Piketty, T. Capital in the Twenty-First Century (Harvard Univ. Press, 2014).

14.Atkinson, A. B. Inequality: What Can Be Done? (Harvard Univ. Press, 2015)

15.Acemoglu, D. \& Restrepo, P. NBER Working Paper No. 22252 (2017); available at http:// go.nature.com/2xjwlwl

16.Allen, R. C. The British Industrial Revolution in Global Perspective (Cambridge Univ. Press, 2009).

Supplementary information accompanies this article online; see go.nature.com/2i5dj4r.

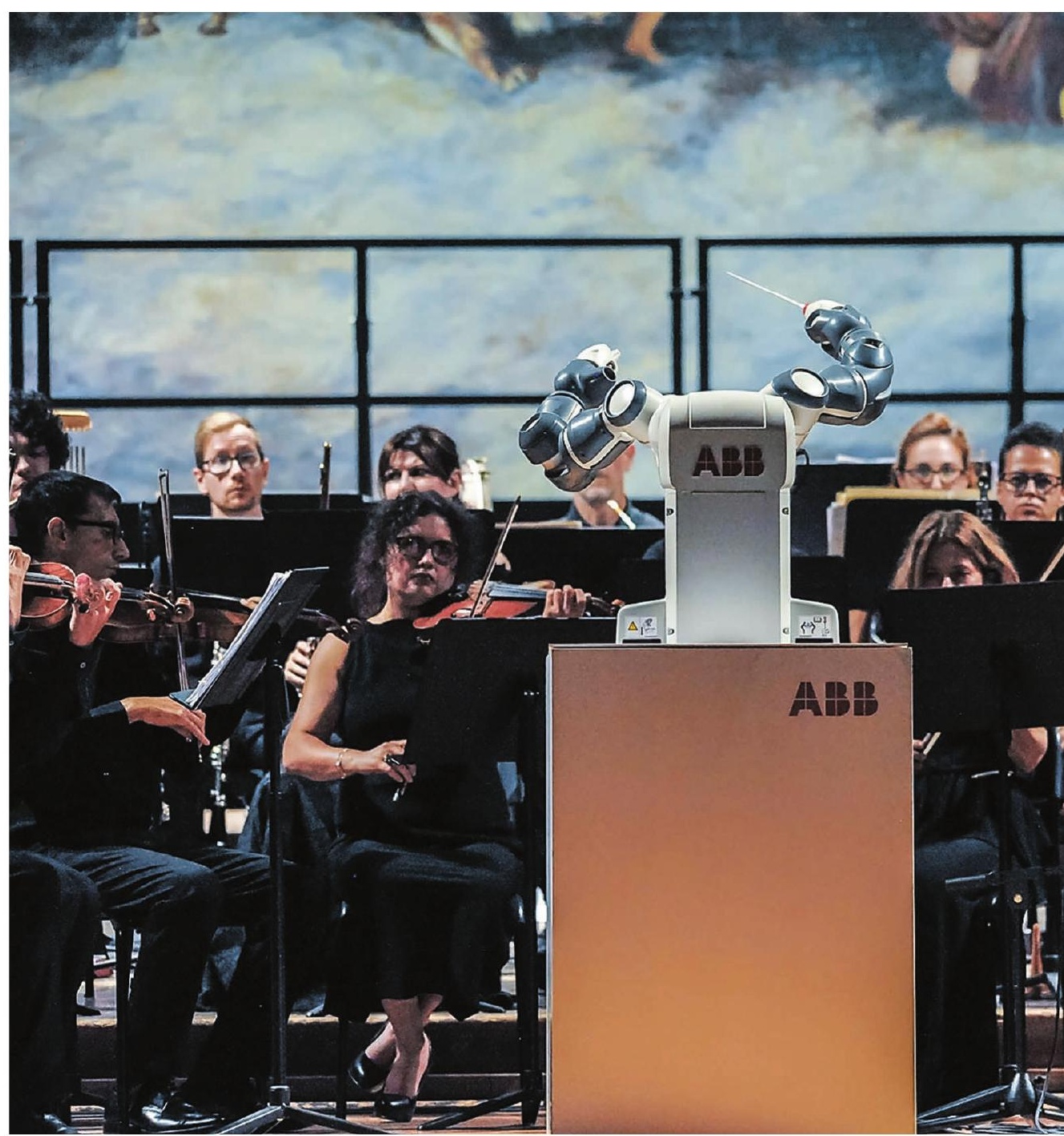

A robot conducts the Orchestra Filarmonica di Lucca at Teatro Verdi in Pisa, Italy, this September.

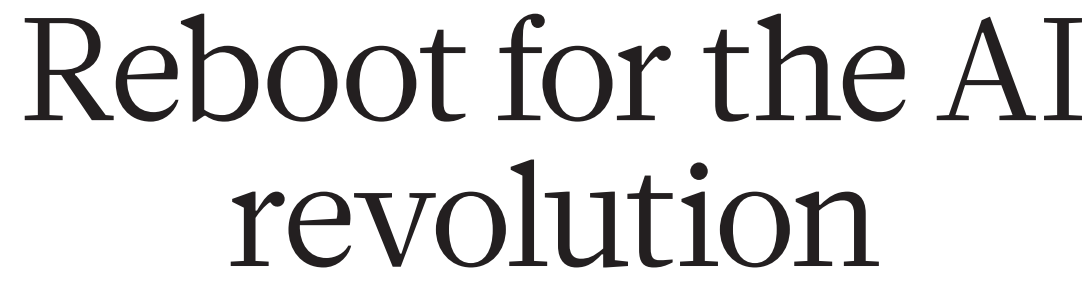

$\mathrm{T}$ The ongoing artificial-intelligence revolution will change almost every line of work, creating enormous social and economic opportunities - and challenges. Some believe that intelligent computers will push humans out of the job market and create a new 'useless class'; others maintain that automation will generate a wide range of new human jobs and greater prosperity for all. Almost everybody agrees that we should take action to prevent the worst-case scenarios.

The automation revolution is emerging from the confluence of two scientific tidal waves. Computer scientists are developing artificial intelligence (AI) algorithms that can learn, analyse massive amounts of data and recognize patterns with superhuman efficiency. At the same time, biologists and social scientists are deciphering human emotions, 


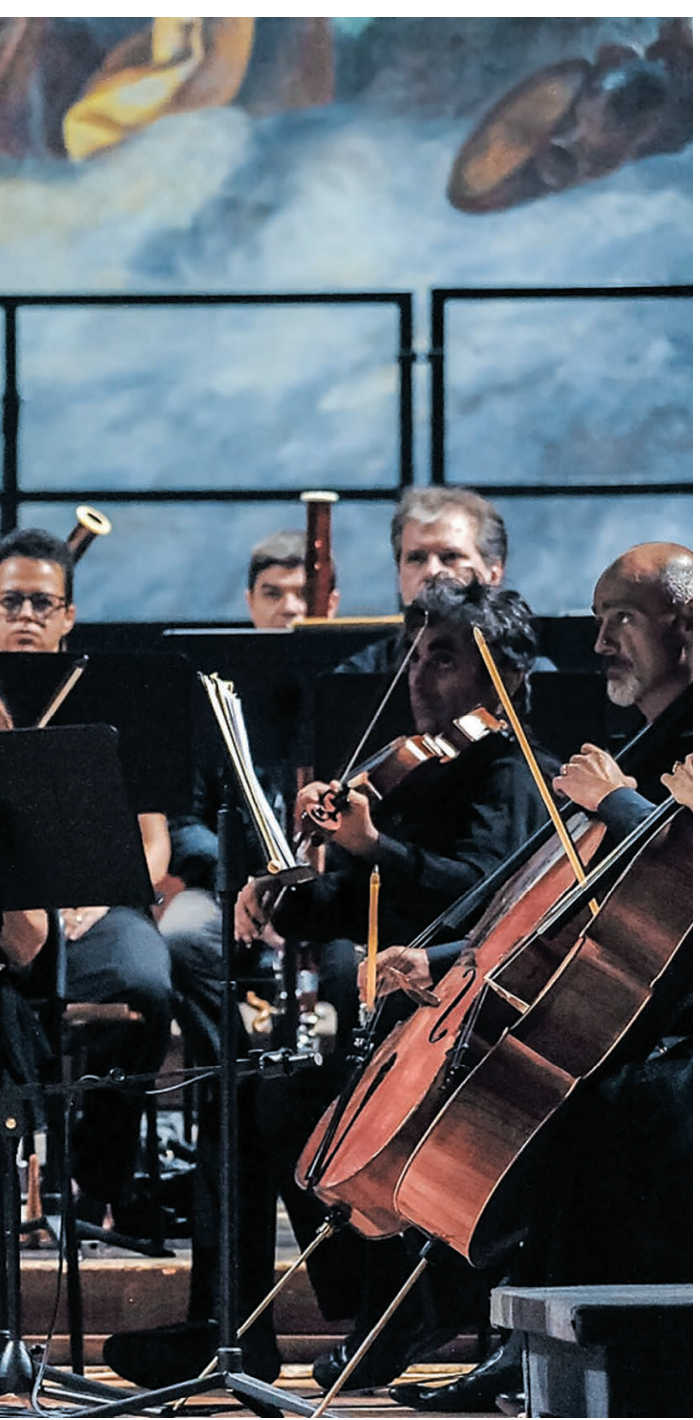

desires and intuitions. The merger of infotech and biotech is giving rise to algorithms that can successfully analyse us and communicate with us, and that may soon outperform human doctors, drivers, soldiers and bankers in such tasks. These algorithms could eventually push hundreds of millions out of the job market.

Governments might decide to deliberately slow down the pace of automation, to lessen the resulting shocks and allow time for readjustments. But it will probably be both impossible and undesirable to prevent automation and job loss completely. That would mean giving up the immense positive potential of AI and robotics. If self-driving vehicles drive more safely and cheaply than humans, it would be counterproductive to ban them just to protect the jobs of taxi and lorry drivers.

A more sensible strategy is to create

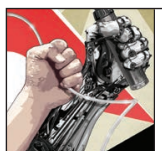

THE FUTURE OF WORK

A Nature special issue new jobs. In particular, as routine jobs are automated, opportunities for new nonroutine jobs will mushroom. For example, general physicians who focus on diagnosing known diseases and administering familiar treatments will probably be replaced by AI doctors. Precisely because of that, there will be more money to pay human experts to do groundbreaking medical research, develop new medications and pioneer innovative surgical techniques.

This calls for economic entrepreneurship and legal dexterity. Above all, it necessitates a revolution in education.

\section{LIFELONG LEARNING}

To make use of the new opportunities, people will need radical, lifelong retraining. The AI revolution won't be a single event after which the job market and the educational system will settle into a new equilibrium. Rather, it will be a cascade of ever-bigger disruptions. Even today, few employees expect to work in the same job for their entire life (see go.nature. com/2ymdvjs). By 2050, not just the idea of 'a job for life', but even the idea of 'a profession for life' might seem antediluvian. It will become increasingly difficult to know what to teach schoolchildren and university students.

Predicting the future was never easy. If you lived in China 1,000 years ago, there were many things you didn't know: the empire might collapse in 50 years; the Khitans might invade, or a new plague might kill millions. Nevertheless, you did know that most people would still work as farmers and weavers, rulers would still need men to fight in their armies and administer their taxes, women would still have few opportunities beyond marriage and life expectancy would still be about 40 years.

Hence, in 1017, poor Chinese parents taught their children how to plant rice or weave silk, and wealthier parents taught their boys how to read and write, or to fight on horseback, and their girls to be modest and obedient housewives. It was obvious that these skills would still be needed. In 2017 , by contrast, we have no such certainties about the future of jobs, gender, economics or even death.

Human psychology, too, might turn out to be a key hurdle. Change is always stressful. Already we face an epidemic of stress and anxiety (see go.nature. com/2z96s57). As the volatility of the job market and of individual careers increases, we may wonder whether everyone will have the emotional stamina necessary for a life of constant flux. We may need more-effective stress-reduction techniques - ranging from drugs through neurofeedback to meditation to cope.

Creating new jobs might prove easier than retraining people to fill them. A huge useless class might appear, owing to both an absolute lack of jobs and a lack of relevant education and mental flexibility.

\section{TEST CASES}

It is particularly important to identify as early as possible the potential winners and losers from new technologies. Rosy overall statistics can hide growing gaps between disparate groups. Automation might have a very different impact on men and women, on 40-somethings and 20-somethings, on the university-educated and the illiterate.

The winners and losers are not the usual suspects. In the clinic, for example, automation might prove more of a threat to doctors than to nurses. Many physicians focus almost exclusively on processing information: they absorb medical data, analyse them and produce a diagnosis. Nurses also need good motor and emotional skills, to give a

"A huge useless
class might
appear, owing to
both an absolute
lack of jobs and
a lack of relevant
education
and mental
flexibility."
painful injection, replace a bandage and listen with care. We will probably have an AI family doctor on our smartphone years before we have a reliable nurse robot $^{1}$

Exploring the relationship between intelligence and consciousness will also be crucial to understanding the economic, professional and ethical rapport between future computers and humans. We are seeing a tremendous development in computer intelligence, but zero development in computer consciousness. Just as aeroplanes fly faster than birds without ever developing feathers, so computers could come to solve problems and even to analyse human feelings much better than humans, without ever developing feelings. Studying these differences will help us to predict what AI can and cannot do, and to decide what should be kept out of its control.

There are a few areas in which AI has already made significant strides that, in my view, offer test cases for the impact of modern automation on the world of work.

In chess, it has been 20 years since IBM's Deep Blue computer thrashed Gary Kasparov. Yet humans still play chess, and 'centaur' teams of humans-plus-AIs can outperform both. This seems at first to bode well for the future: the job market could nurture people who can leverage, rather than compete with, AI. Yet the balance of power in centaur teams is constantly shifting. Computers are becoming so good at chess that the humans are gradually losing value, and could soon become irrelevant. The same thing might happen in other human-AI teams ${ }^{2}$.

Self-driving vehicles are another important test case. The race to produce self-driving 


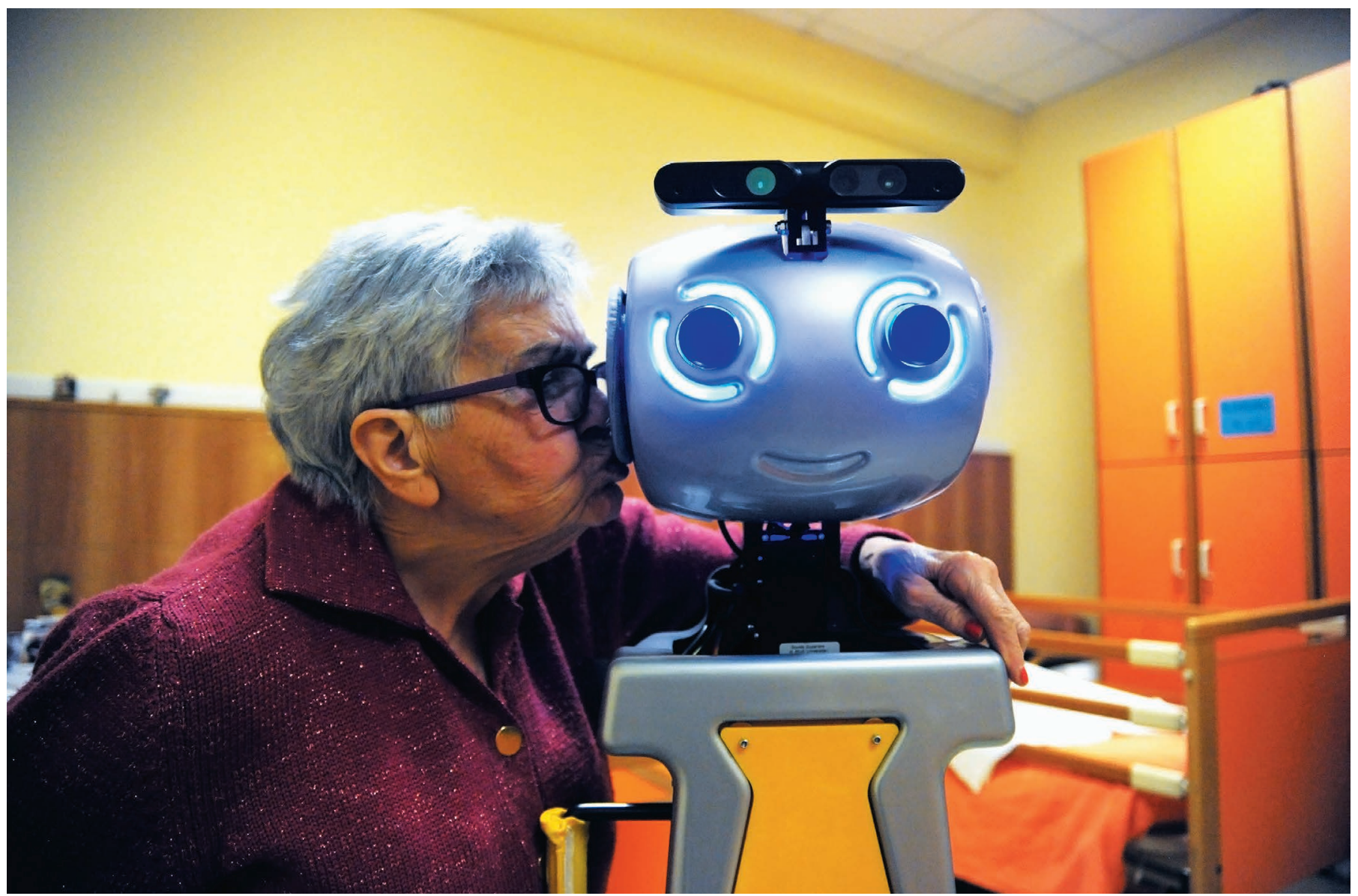

A woman with a robot at an Italian nursing home in 2015.

vehicles now pits old steel giants such as Mercedes-Benz against new silicon giants such as Google. Transport leverages one of the core advantages of AI: connectivity. Even if a single computer-driven car is less competent than a good human driver, a network of computer-driven cars is still likely to be much safer and more efficient than the chaos of fallible human drivers that currently dominates the roads.

Today, about "A careful study 1.25 million people of the military are killed annually in job market car accidents ${ }^{3}$, more might tell us than $90 \%$ of which a lot about are estimated to be potentialfuture caused by human developments errors ${ }^{4}$. When two in the civilian. human drivers economy." approach the same junction, they might miscommunicate and collide. But computer-driven vehicles can be connected - the chances that they might miscommunicate and collide are therefore much smaller. Similarly, it is easier to ensure that automated vehicles comply with rules such as speed limits (not to mention the ban on drink driving), even as those rules change ${ }^{5-7}$.

Self-driving vehicles illustrate two important points. First, that in some fields it might make sense to replace all humans with robots and computers, even if individually some humans do a better job. Second, that when change comes to some realms, it might do so suddenly, not step-wise.

The military is another important bellwether, because armies are early adopters of much technology. Human soldiers carry a very high economic and political price tag, so replacing people with computers on the battlefield has proved attractive. The most advanced armies now increasingly rely on relatively small numbers of experts coupled with sophisticated and autonomous technologies, such as drones, robots, smart bombs, cyberworms and algorithms that sift through a mass of data ${ }^{8,9}$.

This shift has produced new classes of military jobs in maintenance, remote control, programming and cybersecurity. The US armed forces need 30 people to operate every Predator or Reaper drone flying over Syria, and analysing the harvest of information occupies at least 80 more. A careful study of the military job market might tell us a lot about potential future developments in the civilian economy.

\section{NEW ORDER}

With insights gleaned from early warning signs and test cases, scholars should strive to develop new socio-economic models.
The old ones no longer hold. For example, twentieth-century socialism assumed that the working class was crucial to the economy, and socialist thinkers tried to teach the proletariat how to translate its immense economic power into political clout. In the twenty-first century, if the masses lose their economic value they might have to struggle against irrelevance rather than exploitation.

One new model has been gaining increasing attention and popularity: universal basic income (UBI). UBI suggests that the government should tax the rich and big corporations to provide every person with a stipend covering his or her basic needs. This will cushion the poor against job loss and economic dislocation, and protect the rich from populist rage. It will also free the masses to engage in more creative forms of work that might not currently have economic value, or to pursue further education.

In January 2017, Finland began a 2-year experiment, providing 2,000 unemployed citizens with $€ 560$ (US\$657) per month, irrespective of whether they work. Similar experiments are under way in the Canadian province of Ontario, in the Italian city of Livorno and in several Dutch cities ${ }^{10}$.

Of course, such national and municipal schemes might not solve the worst problems. 
Globalization has made people in one country utterly dependent on markets in others, and automation might unravel large parts of this global trade network with disastrous consequences for the weakest links. AI might generate immense wealth in hi-tech hubs such as Silicon Valley and Bangalore, while devastating the econo-

mies of underdeveloped countries that rely on cheap labour, such as Honduras and Bangladesh.

US voters might conceivably agree that taxes paid by tech giants Amazon and Google for their US business should be used to give stipends to unemployed coalminers in Pennsylvania or jobless taxidrivers in New York. But they are unlikely to send their taxes to Honduras. We are still far from having any feasible models for a post-work economy, society or political system, and we don't have much time to formulate them.

In the nineteenth century, the Industrial Revolution created new conditions and problems that none of the existing social, economic and political models could cope with. Consequently, humankind had to develop completely new models - liberal democracies, communist dictatorships and fascist regimes. It took more than a century of terrible wars and revolutions to experiment with these, separate the wheat from the chaff and implement the best solutions.

The challenges posed in the twentyfirst century by the merger of infotech and biotech are arguably bigger than those thrown up by steam engines, railways, electricity and fossil fuels. Given the immense destructive power of our modern civilization, we cannot afford more failed models, world wars and bloody revolutions. We have to do better this time.

Yuval Noah Harari is in the Department of History, Hebrew University of Jerusalem. e-mail:ynharari@mail.huji.ac.il

1. Chui, M., Manyika, J. \& Miremadi, M. McKinsey Quarterly (2016); available at http://go.nature. com/2xt0iio

2. Cowen, T. Marginal Revolution (2013); available at http://go.nature.com/2kzkkgs

3. World Health Organization Global Status Report on Road Safety 2015 (WHO, 2016).

4. Fagnant, D. J. \& Kockelman, K. Transp. Res. Part A Policy Pract. 77, 167-181 (2015).

5. Azimi, S., Bhatia, G., Rajkumar, R. \& Mudalige, P. SAE Int. J. Passenger Cars - Mech. Syst. 4, 406-416 (2011).

6. Kumar, S. et al. SIGCOM Comp. Commun. Rev. 42, 259-270 (2012).

7. Gerla, M., Lee, E. K., Pau, G. \& Lee, U. 2014 IEEE World Forum on Internet of Things (WF-IOT) 241-246 (IEEE, 2014).

8. Hirschauge, O. \& Sheizaf H. Haaretz (2017); available at http://go.nature.com/2xswgrm (in Hebrew).

9. Harel, A. Haaretz (2017); available at http:// go.nature.com/2yaiavo (in Hebrew).

10. Henley, J. The Guardian (2017); available at http://go.nature.com/2kd2pld

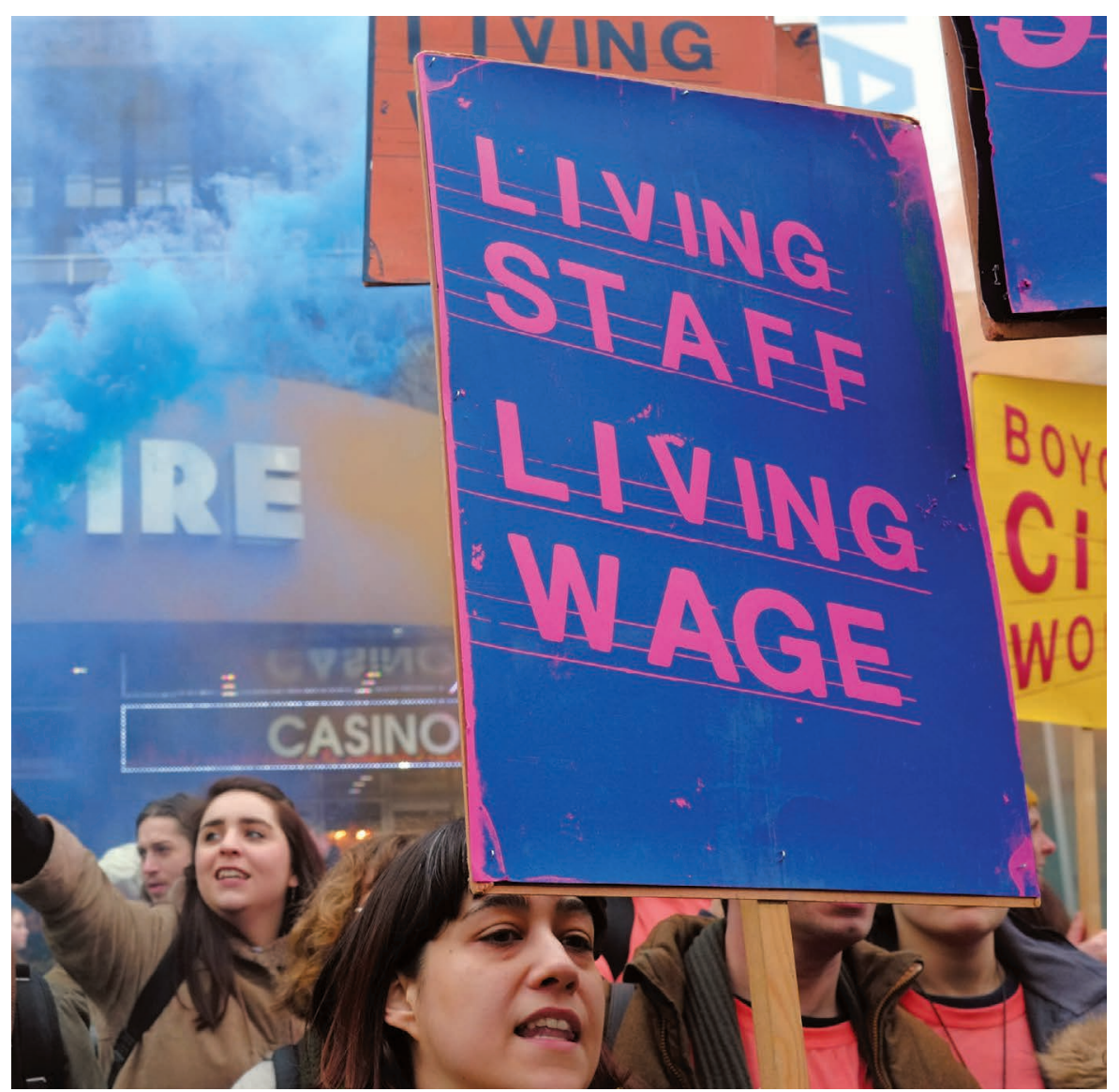

Workers protest in London in February.

\section{The second Renaissance}

\section{Ian Goldin calls on scientists to help society to weather the disruptive transformations afoot.}

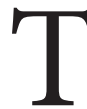

The Renaissance that began in Europe in the mid-1400s and ended in the early 1500 s brought a radical transformation of the sciences, the humanities and politics. Building on the invention of the printing press and cheap paper, information was democratized, there was a hunger for literacy and the Catholic Church's near-monopoly on knowledge was challenged. The resulting breakthroughs took Europe from being one of the more backward regions of the world to being the most advanced by far, within just 80 years.

But it ended in tears. Extremists, pointing

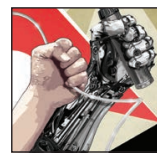

THE FUTURE OF WORK

A Nature special issue to growing inequalities and the corruption of the elite, called for a return to spiritual values. In Italy, thousands of artworks and books were burned, branded as irreverent. Across Europe, rising intolerance of scientists, intellectuals, foreigners and ethnic minorities became the norm, with religious wars and inquisitions playing out over the following centuries.

In my view, many parts of the world are now in the middle of a second Renaissance. This one is seeing even faster change than the last, and across the entire globe. History tells us that it will be disruptive. It will bring immense benefits and it will be highly destabilizing. We should expect more extremism and the rise of potentially catastrophic risks.

Innovation today is happening faster than ever, driven by the unlocking of individual $>$ 